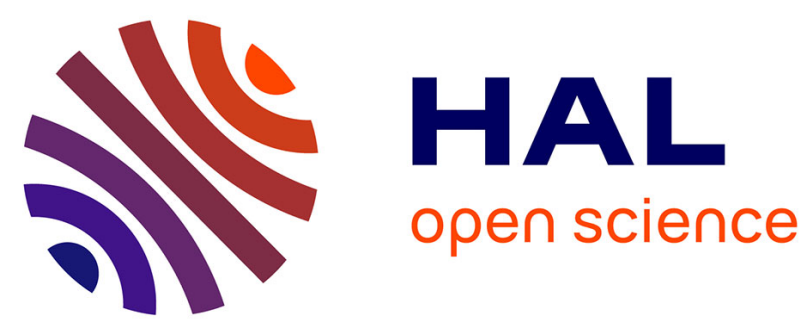

\title{
MAGNETOCALORIC EFFECT AND CRITICAL PHENOMENA OF IRON, COBALT AND NICKEL NEAR THE CURIE TEMPERATURE
}

W. Rocker, R. Kohlhaas, H. Schöpgens

\section{> To cite this version:}

W. Rocker, R. Kohlhaas, H. Schöpgens. MAGNETOCALORIC EFFECT AND CRITICAL PHENOMENA OF IRON, COBALT AND NICKEL NEAR THE CURIE TEMPERATURE. Journal de Physique Colloques, 1971, 32 (C1), pp.C1-652-C1-653. 10.1051/jphyscol:19711225 . jpa-00214052

HAL Id: jpa-00214052

https://hal.science/jpa-00214052

Submitted on 1 Jan 1971

HAL is a multi-disciplinary open access archive for the deposit and dissemination of scientific research documents, whether they are published or not. The documents may come from teaching and research institutions in France or abroad, or from public or private research centers.
L'archive ouverte pluridisciplinaire HAL, est destinée au dépôt et à la diffusion de documents scientifiques de niveau recherche, publiés ou non, émanant des établissements d'enseignement et de recherche français ou étrangers, des laboratoires publics ou privés. 


\title{
MAGNETOCALORIC EFFECT AND CRITICAL PHENOMENA OF IRON, COBALT AND NICKEL NEAR THE CURIE TEMPERATURE
}

\author{
by W. ROCKER, R. KOHLHAAS and H. W. SCHÖPGENS \\ Max-Planck-Institut für Eisenforschung, Düsseldorf and Abt. Metallphysik im II.Physikalischen \\ Institut der Universität Köln
}

Résumé. - Les propriétés magnétiques de $\mathrm{Fe}$, Co et $\mathrm{Ni}$ et l'effet magnétocalorique ont été étudiés dans les environs du point de Curie. L'aimantation spontanée et l'inverse de la susceptibilité initiale ont été calculées. Les exposants $\beta$, $\gamma, \delta$ et $\pi$ ont été donnés.

Abstract. - The magnetic properties of $\mathrm{Fe}, \mathrm{Co}$ and $\mathrm{Ni}$ have been measured together with the magnetocaloric effect in the neighbourhood of the Curie temperature. Spontaneous magnetization and reciprocal initial susceptibility have been computed. The critical indices $\beta, \gamma, \delta$ and $\pi$ are given.

Till now there have been given uniform exponents $\beta$ and $\gamma$ concerning the magnetization-field-temperature behaviour of a ferromagnetic in a great temperature range about the critical point. These critical indices were combinable with scaling laws and they allowed to calculate the exponents $\delta$ of the magnetization and $\pi$ of the magnetocaloric effect at $T_{c}$. Following theoretical discussions of Kadanoff [1] two values for $\beta$ were to be expected according to the distance from the critical point.

This supposition was confirmed by exact measurements of Arajs [2] on nickel from which $\beta$ was calculated :

$\beta=0.50$ for $\varepsilon=\left|1-T / T_{\mathrm{c}}\right|=4 \times 10^{-4} \ldots 5 \times 10^{-3}$

$\beta=0.34$ for $\varepsilon=\left|1-T / T_{\mathrm{c}}\right|=5 \times 10^{-3} \ldots 3 \times 10^{-1}$.

We have studied with a modified Faraday force technique the magnetization behaviour of $\mathrm{Fe}, \mathrm{Co}$ and $\mathrm{Ni}$ spheres together with the magnetocaloric effect in a wide temperature range about the Curie point with external fields from 100 to 25000 Oe. The apparatus and the measuring procedure have been described by Lange [3]. Fig. 1 shows some of these magnetization curves of $\mathrm{Fe}, \mathrm{Co}$ and $\mathrm{Ni}$ as a function of temperature with the external field as a parameter. In fig. 2 there are plotted some curves of the magne-

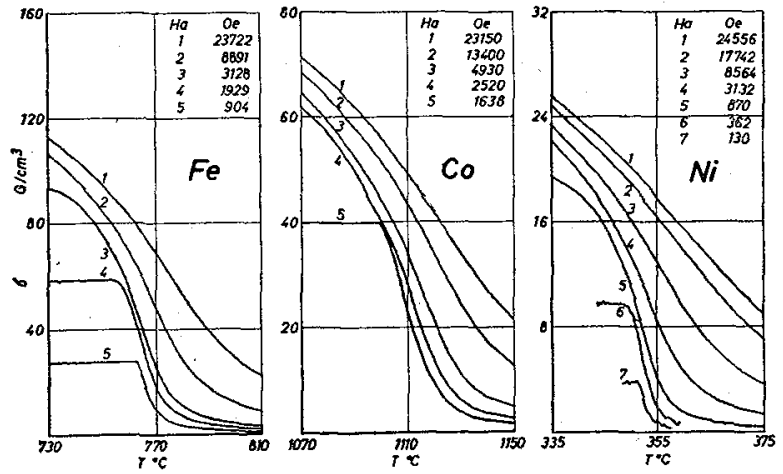

FIG. 1. - Specific magnetization of $\mathrm{Fe}$, $\mathrm{Co}$ and Ni plotted vs temperature with external field as a parameter tocaloric effect as a function of temperature without field.
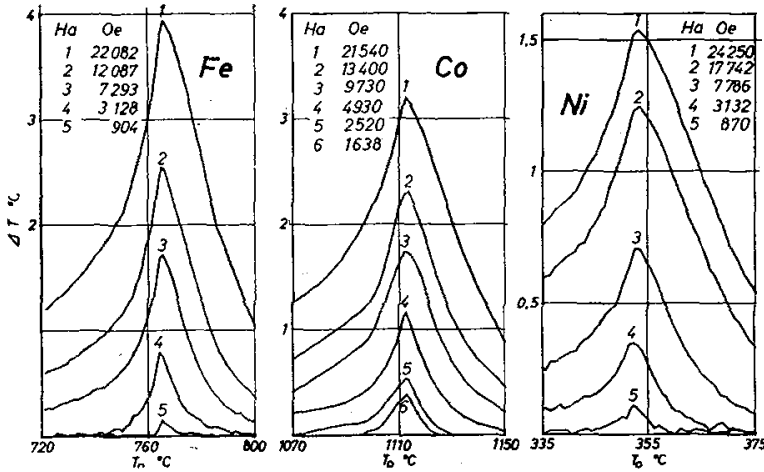

Fig. 2. - Magnetocaloric effect of Fe, Co and Ni plotted vs temperature $T_{0}$ without field.

The numerous automatically measured points were given into a PDP-10 digital computer to calculate according to Kouvel [4] with a parabolic extrapolation process [3] the temperature dependence of the spontaneous magnetization $\sigma_{0}$ and the reciprocal initial susceptibility $1 / \chi_{0}$. In fig. 3 there are plotted the square of spontaneous magnetization and the reciprocal initial susceptibility versus temperature. The temperature dependence of both quantities is not linear in the whole temperature range.

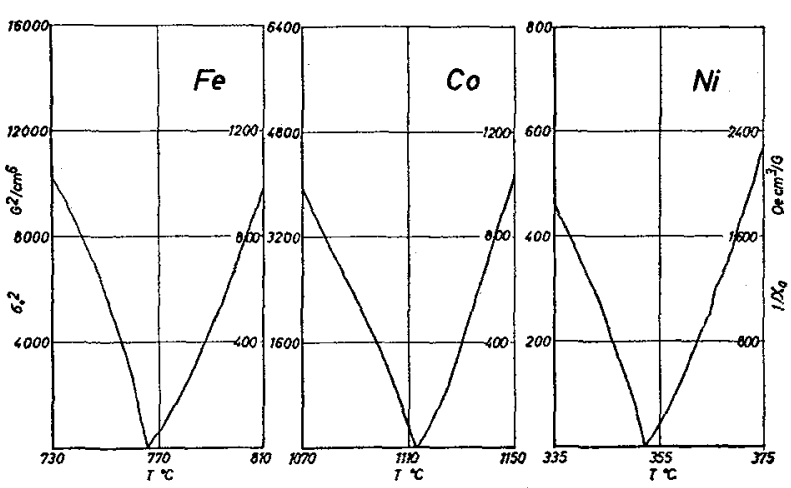

Fig. 3. - Square of spontaneous magnetization and reciprocal initial susceptibility vs temperature. 
A $\log -\log$ plot of $\sigma_{0}$ vs $\varepsilon=\left|1-T / T_{\mathrm{c}}\right|$ respectively of $1 / \chi_{0}$ vs $\varepsilon$ shown in fig. 4 allows the deter-
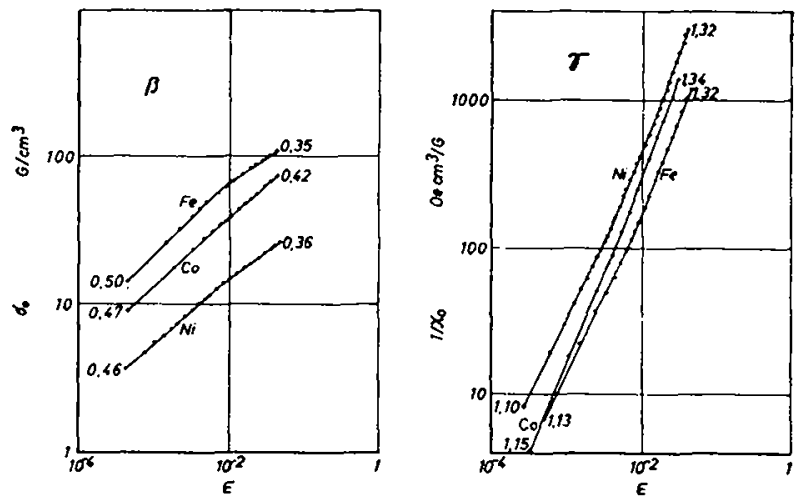

FIG. 4. - Log-log plot of spontaneous magnetization and reciprocal initial susceptibility vs $\varepsilon=\left|1-T / T_{\mathrm{c}}\right|$.

mination of the exponents $\beta$ and $\gamma$. There is no uniform value for $\beta$ and $\gamma$ in the whole investigated temperature range. Fig. 5 shows the log-log plot of the magnetization at $T_{\mathrm{c}}$ vs internal field and of the magnetocaloric effect vs magnetization to determine the critical indices $\delta$ and $\pi$.

In the table there are given the exact values of the determined exponents $\beta, \gamma, \delta$ and $\pi$ and the ranges of their validity. The mean deviation of these values is about $\pm 3 \%$. Moreover the values for $\delta$ and $\pi$ calculated with the scaling laws
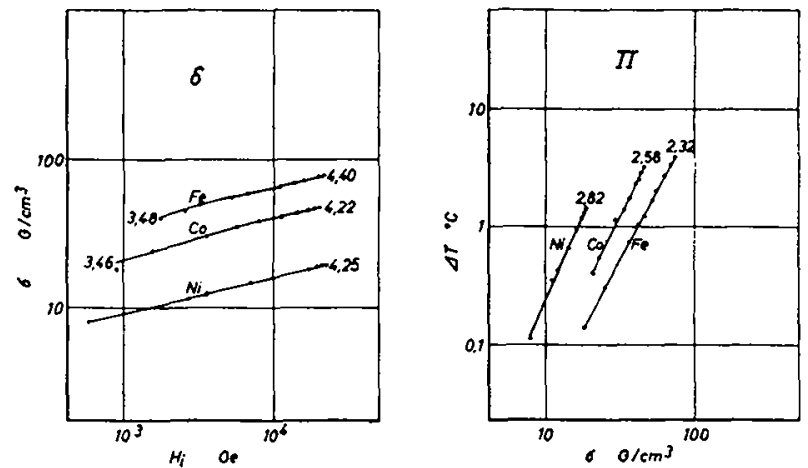

Fig. 5. - Log-log plot of magnetization vs internal field and magnetocaloric effect vs magnetization at $T_{\mathrm{c}}$.

$$
\begin{aligned}
& \delta=1+\gamma / \beta \text { and } \\
& \pi=2+(\gamma-1) / \beta \text { (according to Wohlfarth [5]) }
\end{aligned}
$$

by using the experimental values for $\beta$ and $\gamma$ are noticed in parenthesis. The agreement between the calculated and the experimental values for $\delta$ and $\pi$ is not very satisfactory.

To conclude there is to remark that the exact behaviour of a ferromagnetic transition metal at the critical point seems to be more complicated than it was first assumed. Here is the behaviour near $T_{\mathrm{c}}$ not exactly to be described by the scaling laws.

Acknowledgements. - We thank Prof. Arajs for sending us the preprint [2].

TABLE

Experimental values of the exponents $\beta, \gamma, \delta$ and $\pi$ and range of validity. In parenthesis : values for $\delta$ and $\pi$ calculated by using the scaling laws and the experimental values for $\beta$ and $\gamma$.

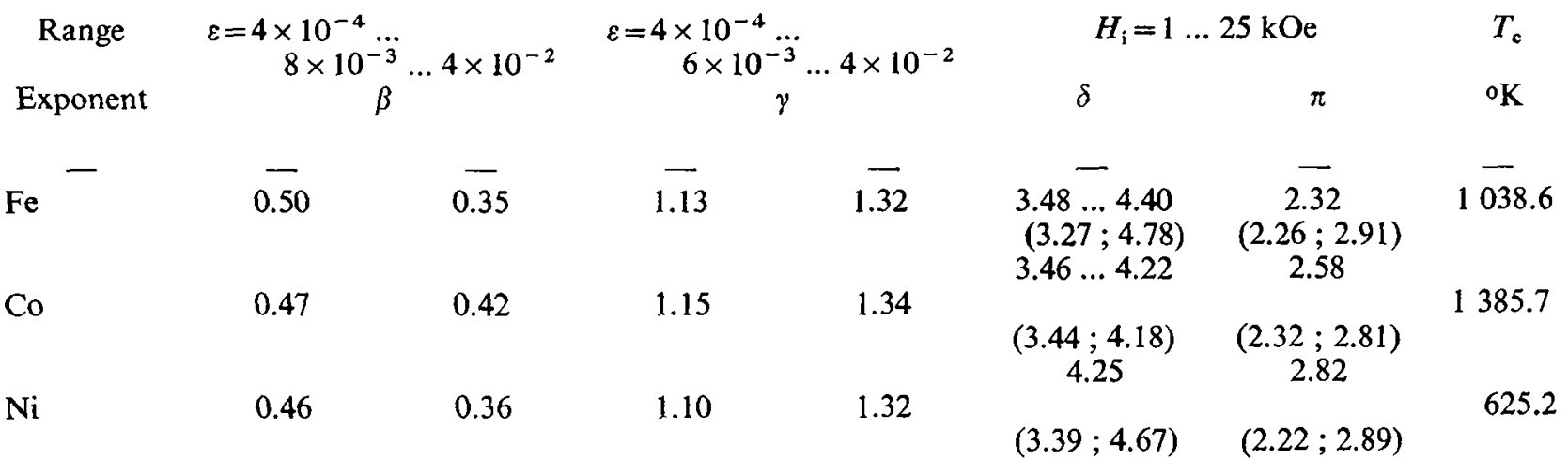

\section{References}

[1] Kadanoff (L. P.), Götze (W.), Hamblen (D.), Hecht (R.), Lewis (E. A. S.), Palciauskas (V. V.), RAYL (M.), SWIFT (J.), ASPNES (D.) and Kane (J.), Rev. Mod. Phys., 1967, 39, 395.

[2] Arajs (S.), Tehan (B. L.), ANDerson (E. E.) and Stelmach (A. A.), to be published.
[3] LANGe (H.), KohlhaAs (R.) and Rocker (W.), Forschungsbericht des Landes Nordrhein-Westfalen, 1969, 1992.

[4] Kouvel (J. S.), General Electric Research Laboratory Report No. 57-RL-1799, 1957.

[5] Mathon (J.) and Wohlfarth (E. P.), J. Phys. C, $1969,2,1647$. 